\title{
Research on the Influencing Factors of Kindergarten on Children's Physical Activity
}

\author{
Baoyu Lan, Xiaoyan Guo \\ School of Physical Education and Health Science, Zhejiang Normal University, Jinhua, China \\ Email: 1144073976@qq.com
}

How to cite this paper: Lan, B.Y. and Guo, X.Y. (2021) Research on the Influencing Factors of Kindergarten on Children's Physical Activity. Open Access Library Journal, 8: e7832.

https://doi.org/10.4236/oalib.1107832

Received: August 5, 2021

Accepted: August 27, 2021

Published: August 30, 2021

Copyright $\odot 2021$ by author(s) and Open Access Library Inc.

This work is licensed under the Creative Commons Attribution International License (CC BY 4.0).

http://creativecommons.org/licenses/by/4.0/

\begin{abstract}
With the rapid development of society and the change of people's lifestyle, preschoolers between the ages of 3 and 6 are also deeply affected by the lack of physical activity. How to ensure children's physical activity level has become an important research issue of children's physical health. Based on this, this paper uses the literature method to study the factors influencing the physical activity of 3 - 6 years old children in kindergarten, and explore the favorable factors to enhance the physical activity level of children, so as to provide theoretical reference for kindergartens and other kindergartens and promote the healthy growth of children.
\end{abstract}

\section{Subject Areas}

Physical Education

\section{Keywords}

Children, Physical Activity, The Kindergarten

\section{Introduction}

With the rapid development of society and economy, as well as the promulgations of relevant policies, early childhood education has become more diversified, which shows its importance. Children are the basic stage of one's life, and their development will have a direct impact on one's life. 3 to 6 years old preschool children are in the stage of rapid physical development, mainly in the body, movement, intelligence, cognition, perception, psychology and other aspects. Numerous studies have confirmed that physical activities at this stage have a positive impact on children's growth and development, physical quality, body cognition and perception, physical health and comprehensive development, and lay a foundation for future physical exercise, learning and training, so as to bet- 
ter study, life and work [1]-[7].

Studies have shown that physical inactivity not only affects the current physical health of children and adolescents, but also is an important factor leading to obesity and chronic cardiovascular diseases in contemporary children and adolescents [8]. According to the literature review, there are many factors affecting physical activity, but most of the researches of scholars focus on the single factor that affects children's physical activity, without taking into account the different effects of different factors on children's physical activity. For example, Wu Haijun, Gao Yun and Zhao Yanmin studied the individual factors of children's physical activity ability, Hong Jintao and Wu Xuelean studied family factors, Wang Ling studied teachers' factors, and Zhao Xing and Lu Canhua studied the sports environment. Moreover, it is found that the influence of kindergarten on children's physical activity level is particularly noteworthy. Kindergarten is the environment where children aged $3-6$ are exposed to for the longest time in a day, and it is also the place where most physical activities occur [9]. Therefore, this study explores the influencing factors of children's physical activity from the four aspects of individual factors, teacher factors, facilities and environment factors and family factors in kindergarten, so as to provide theoretical basis and reference for improving children's physical activity intensity level and physical activity time in kindergarten.

\section{Factors Influencing Children's Physical Activity Level}

\subsection{Personal Factors}

Children's physical activity in kindergarten is affected by gender, age, BMI and motor skill development. There was a significant correlation between gender and physical activity. The study believed that the level of physical activity intensity and the time spent on physical activity of boys were greater than that of girls. Compared with boys, girls spend more time sitting and less time in physical activity [10] [11] [12] [13], indicating that boys are more active than girls. At the same time, the overall level of physical activity of boys and girls showed a decreasing trend with age [9] [12] [14]. Gender should therefore be considered as a factor in physical activity arrangements for children in kindergartens. In young children in the study of relationship between BMI and physical activity, studies have shown that BMI (normal, overweight, obesity and physical activity levels show significant differences, present two different results: XiaoJun ship [14] in the research of preschool children's physical activity and motor skills, the relationship between obesity in children of high strength showed a negative correlation between physical activity and BMI; There are also some scholars who believe that there is no statistical significance between physical activity intensity level and BMI (normal, overweight, obese) [15]. The contradictory results of this study may be due to the differences in participants and data collection, so further research is needed. In the study of motor skill development, there is a positive correlation between physical activity intensity level and motor skill devel- 
opment. The level and total time of moderate to high intensity physical activity of preschoolers aged 3 - 6 years were significantly correlated with basic motor skill level [14]. The longer the duration of high intensity physical activity, the more advanced the level of motor development; Children with shorter physical activity time lag behind in motor development [9]. Among the personal factors, motor skill development is an important factor affecting children's physical activity ability. Therefore, children's physical activity intensity level and total physical activity time have a direct impact on children's motor skill development.

\subsection{Family Factors}

Family is an important factor affecting the level of physical activity of children and adolescents. For families, in addition to providing material support to children, parents' own exercise level, parents' attitude towards exercise and parents' physical education guidance will also affect children's exercise behaviors [16]. Therefore, this paper mainly explores whether parents' PA (physical activity) level, parents' attitude and parents' physical education guidance will produce significant differences in children's physical activity in kindergarten. Combing literature found that learning about family level of children in the kindergarten are the influence of physical activity, the results of the study contradiction: domestic scholars Zhou Jialin [9] research found that parents' physical activity levels did not affect physical activity within the children in the kindergarten, and study abroad do show the differences of two different results: First, the physical activity level of the mother can promote the physical activity intensity level of the girl, while the father has no effect [17]. Second, father's physical activity level will have an impact on children's physical activity level, while mother's physical activity level will not have an impact on children's physical activity in kindergarten [18]. Although some studies believe that parents' attitudes towards exercise and their children's exercise have no influence on children's physical activities in kindergartens [9], some studies have found that parents' physical education guidance to children has positive significance in promoting the development of physical, psychological, intellectual and comprehensive qualities [2]. The above results may be caused by other factors such as participants and the environment atmosphere in the kindergarten, so more scholars need to further explore the family level.

\subsection{Teacher Factors}

The improvement of children's physical activity level has a direct impact on children's guidance and care by adults. Kindergarten is the main place for children to do physical activities except for their families, so teachers are an important factor influencing children's physical activity except for parents [9] [19]. The influencing factors of teachers are divided into three aspects: teachers' organization and guidance, relevant sports knowledge and physical activity level. 
In the process of the study, it was found that the agility, jumping ability, movement speed and control of children's small muscles were positively correlated with teachers' organization and guidance. In addition, teacher-child interaction has a certain correlation with children's exercise level, which is mainly reflected in children's overall coordination, small muscle agility, jumping ability, motor speed, motor control and other aspects [19]. Among them, teachers' encouragement plays a positive role in promoting children's participation in physical activities, which is manifested in two aspects: verbal encouragement and action encouragement [13]. In the process of teacher-child interaction, the higher the expectation of teachers on the effect of children, the higher the level of physical activity of children [13]. In addition, the higher the teacher's exercise-guided self-efficacy, the higher the children's physical activity level [13]. In the relevant research on the PE knowledge of preschool teachers, some scholars point out that the PE knowledge and physical activity level of preschool teachers will have an impact on children. Teachers who score high on PE knowledge and believe that physical activity can bring benefits can design a higher level of physical activity content to improve the physical activity level of children. In addition, children are a group that lacks autonomy and is good at imitation. The sports performance of kindergarten teachers with strong physical activity level in their daily work will bring important positive influence to children. In addition, the investigation and research found that in kindergartens without full-time PE teachers, children's physical activities are higher than those with full-time PE teachers. The reason is that full-time PE teachers tend to structure the curriculum, while non-full-time PE teachers give play to children's independent initiative [9]. Kindergarten teachers' sports behavior plays a positive guiding role in children's physical activity in kindergarten and can promote children's physical activity level.

\subsection{Environmental Factors of Facilities in Kindergarten}

Students spend most of their non-sleeping time at school, which provides opportunities for physical activity in addition to teaching subjects characterized by sedentary behavior. The school is regarded as the main place to promote students' physical activity [20]. This study mainly expounds the relationship between physical activities in kindergartens and children from three aspects, including field area, sports facilities and sports environment. There is no significant difference between different site area and physical activities of kindergarten children [9]. Although children are more inclined to choose large exercise areas, there is no significant difference between different area sizes and children's physical activities [21], so the impact of field area on children's physical activities is small. Various facilities are placed in the sports facilities area, such as amusement facilities area, open area, sand play area, climbing area, etc., which are the main sports environment contributing to the physical activity intensity, and also the main place for children to carry out outdoor activities. Different areas contribute different levels of physical activity intensity: children in the 
recreation facilities area produce the smallest amount of physical activity; the open area has the largest number of people playing and the physical activity intensity can reach the moderate level of physical activity; climbing area is the area that can contribute the most intense physical activity, but it is less attractive to children [9] [12] [22]. In the sports environment of kindergarten, it is mainly composed of indoor and outdoor. The indoor environment is mainly dominated by classes and the intensity of physical activities is small, while the outdoor environment of kindergarten is the main space for children's activities. Among them, the natural environment in the outdoor environment of kindergarten is the most attractive to children [9] [23], and the display of landscape, color collocation and image design in the outdoor environment have a positive impact on children's psychology and physiology [23]. In the sports environment, children have the highest need for the natural environment of outdoor environment, generally like the natural elements, and the outdoor environment is full of exploration, children's interest and participation [9] [22] [23].

\section{Discussion}

In today's travel convenience and young children caused by sedentary during the learning process as well as other factors caused by the screen use for a long period of time, make its physical activity decrease, but should not be so some factors and reduce their physical activity, therefore, children should maintain necessary to have their physical activity, to improve children's physical health level and comprehensive development. Based on this, through the exploration of four factors affecting children's physical activity level, to provide a theoretical basis for improving children's physical activity level, the conclusions are as follows:

1) In the arrangement of children's physical activities, it is necessary to consider children's gender, age differences and their own BMI, especially to pay attention to the relationship between motor skill development and physical activity intensity and time.

2) In previous studies, the influence of family factors on children's physical activity is controversial, which deserves more scholars' attention. At the same time in the "National Family education guidance outline" clearly pointed out that guide parents actively lead children to carry out sports activities. Therefore, this paper believes that family factors are very important for the cultivation of children's interest in sports.

3) Kindergarten teachers' organizing and guiding ability, physical activity level and physical education knowledge ability play a positive role in promoting children's physical activity.

4) According to the study, among the many factors affecting children's physical activities in kindergarten, outdoor environment is an important factor for children to exercise. Sports facilities and site area in kindergarten are incorporated into the outdoor environment, and a large area, multi-facility and natural environment oriented sports scene is designed. It is characterized by supporting 
children's free exploration and assisted by reasonable guidance to improve children's physical activity intensity and physical activity time in the kindergarten, and at the same time to meet children's psychological needs and promote their comprehensive development of physical and mental health.

\section{Conclusion}

To sum up, this study on the infant's ability to physical activity will be the basis of a single summarized influence factors and comprehensive analysis, to explore the factors of the influence degree of the infant's ability to their own physical activity, and the above conclusion, for the kindergarten in order to promote children's physical activity in individuals, families, teachers, sports environment, etc., to provide theoretical reference to promote the comprehensive development. However, there are still some deficiencies in this study. First of all, this study is a review study. Although the summarized factors are complete, there is no empirical research. Second, there is no research on the relationship between the various factors. Therefore, further empirical research needs to be carried out, and the correlation between various factors should be designed into the research, so as to promote the development of children's physical activity ability.

\section{Conflicts of Interest}

The authors declare no conflicts of interest.

\section{References}

[1] Zhao, Y., Zhang, B., Chang, W., Wang, H. and Liang, G. (2021) The Correlation between Basic Motor Skills and Physical Fitness in 3-6 Years Old Children. Journal of Shandong Physical Education University, 37, 102-111.

[2] Wang, M. (2021) Research on Parental Physical Education Guidance Strategy of 3-6 Year Old Children in Wuhan Kindergarten. Yunnan Normal University, Kunming.

[3] Gao, Y. (2020) Study on the Influence of Rough Movement Development on Physical Fitness of 3-6 Years Old Children. Henan University, Kaifeng.

[4] Xu, R., Li, D., Ding, D. and Zhao, G. (2010) Study on an Integrated School-FamilyCommunity Intervention on Obesity-Related Behaviors of Primary School Pupils. Environmental and Occupational Medicine, 27, 342-345.

[5] Puder, J.J., Marquesvidal, P., Schindler, C., Zahner, L. Niederer, I., Bürgi, F., et al. (2011) Effect of Multidimensional Lifestyle Intervention on Fitness and Adiposity in Predominantly Migrant Preschool Controlled Trial in Children with Controlled Randomness. BMJ British Medical Journal, 343, Article No. d6195. https://doi.org/10.1136/bmj.d6195

[6] Zeng, N., Ayyub, M., Sun, H., Wen, X., Xiang, P. and Gao, Z. (2017) Effects of Physical Activity on Motor Skills and Cognitive Development in Early Childhood. BioMed Research International, 2017, Article ID: 2760716. https://doi.org/10.1155/2017/2760716

[7] Alvarez-Bueno, C., Pesce, C., Cavero-Redondoi, I., Sánchez-López, M., GarridoMiguel, M. and Martínez-Vizcaíno, V. (2017) Academic Achievement and Physical Activity. Pediatrics, 140, Article ID: e20171498. 
https://doi.org/10.1542/peds.2017-1498

[8] Guo, Q. and Wang, X. (2015) Research on Physical Activity in Children and Adolescents: An Epidemiological Perspective. Journal of Sports Science, 35, 58-73.

[9] Zhou, J. (2018) Research on the Influence of Outdoor Environment in Kindergarten on Children's Physical Activities. Beijing Sport University, Beijing.

[10] He, G., Huang, Y., Wang, X. and Feng, Y. (2015) Children's Physical Activity and Residential Built Environment in Hong Kong: A Preliminary Study Using GIS. Chinese Journal of Sports Medicine, 34, 431-436.

[11] Lu, C. (2020) Intensity Level and Related Influencing Factors of Different Types of Outdoor Physical Activities in Kindergartens. Knowledge Library, No. 24, 26+28.

[12] Zhao, X., Zhao, S., Luo, D. and Zhou, J. (2016) Intensity Level and Related Influencing Factors of Different Types of Outdoor Physical Activities in Kindergartens. Physical Education Science, 36, 34-41.

[13] Li, Z., Liang, H., Cheng, S. and Xu, Y. (2016) A Study on Psychological Factors Affecting Children's Physical Activity level. Zhejiang Sports Science, 38, 99-104.

[14] Xiao, J. (2020) Research on the Relationship between Physical Activity, Basic Motor Skills and Obesity in Preschool Children. Qufu Normal University, Qufu.

[15] Li, S. (2013) Analysis and Research on Physical Activity and Related Factors of Middle School Students with Acceleration Sensor. Nanjing University of Physical Education, Nanjing.

[16] Hong, J. (2010) Study on the Status of Physical Activity and Sedentary Behavior and Affecting Factors among Part of High School Students in Shanghai. Shanghai Institute of Physical Education, Shanghai.

[17] Bois, J.E., Sarrazin, P.G., Brustad, R.J., Trouilloud, D.O. and Cury, F. (2005) Elementary Schoolchildren's Perceived Competence and Physical Activity Involvement: The Influence of Parents' Role Modelling Behaviours and Perceptions of Their Childs Competence. Psychology of Sport \& Exercise, 6, 381-397. https://doi.org/10.1016/j.psychsport.2004.03.003

[18] Taylor, R.W., Murdoch, L., Carter, P., Gerrard, D.F., Williams, S.M. and Taylor, B.J. (2009) Longitudinal Study of Physical Activity and Inactivity in Preschoolers: The FLAME Study. Medicine \& Science in Sports \& Exercise, 41, 96-102. https://doi.org/10.1249/MSS.0b013e3181849d81

[19] Wang, F. (2014) Study on the Relationship between Children's Motor Ability and Kindergarten Sports Environment Quality. Zhejiang Normal University, Jinhua.

[20] Wang, J., Wang, J., Wang, J., et al. (2009) The Impact of Physical Activity on School Health Management. Journal of Nanjing Institute of Physical Education (Social Science Edition), 23, 13-20+34.

[21] Qian, Y. and Cai, K. (2018) Play Big Area and Share Happiness Together-On Children's Harmonious Development in Outdoor Big Area Activities. Science for the Public (Science Education), No. 9, 70.

[22] Luo, D. (2020) Research on Outdoor Activities Organization of Kindergarten Class. Liaoning Normal University, Dalian.

[23] Zhou, X. (2020) Research on the Characteristics of Outdoor Activities in Kindergarten from the Perspective of Children. Liaoning Normal University, Dalian. 